\title{
Notes on the vocalizations of Sedge Wren (Cistothorus platensis)
}

Peter Boesman

In the following we briefly analyze and compare voice of the different races of Sedge Wren (Cistothorus platensis). We also try to quantify the extent of any vocal differences using the criteria proposed by Tobias et al. (2010), as a support for taxonomic review.

We have made use of sound recordings available on-line from Xeno Canto (XC).

Our main interest is to compare song of race stellaris vs. all other races:

stellaris

Song is fairly uniform and simple over its entire range: a few "tsik" notes followed by a rattled series of notes (pace somewhat variable among individuals, switching pace within same song also occurs but not that frequently). Some examples:

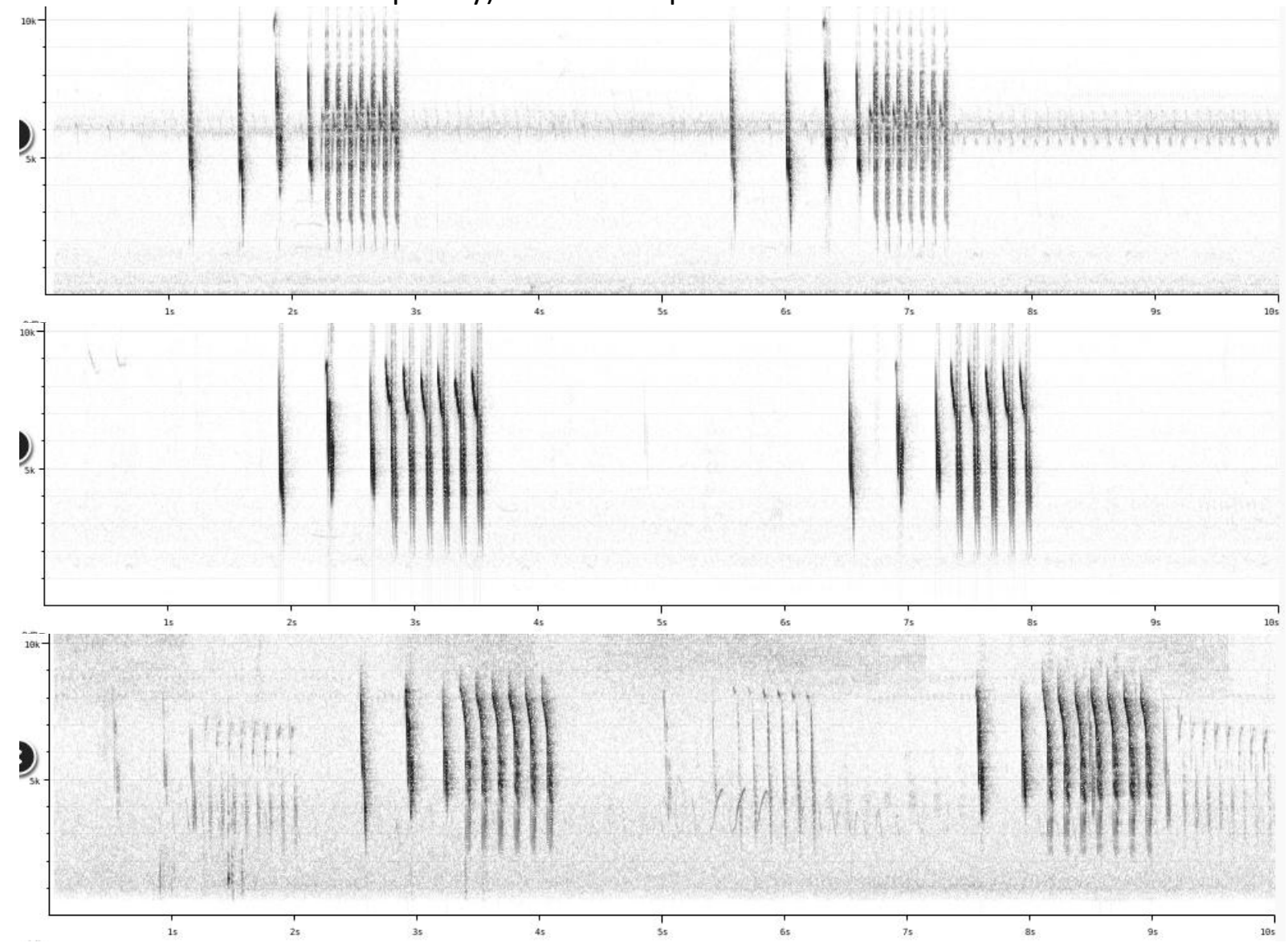

All other races seem to have a much more complex song, combining many different phrases which consist of several note types within each phrase. Some examples from North to South: 


\section{HANDBOOK OF THE \\ BIRDPlu WU WRLD ORNITHOLOGICAL NOTES}

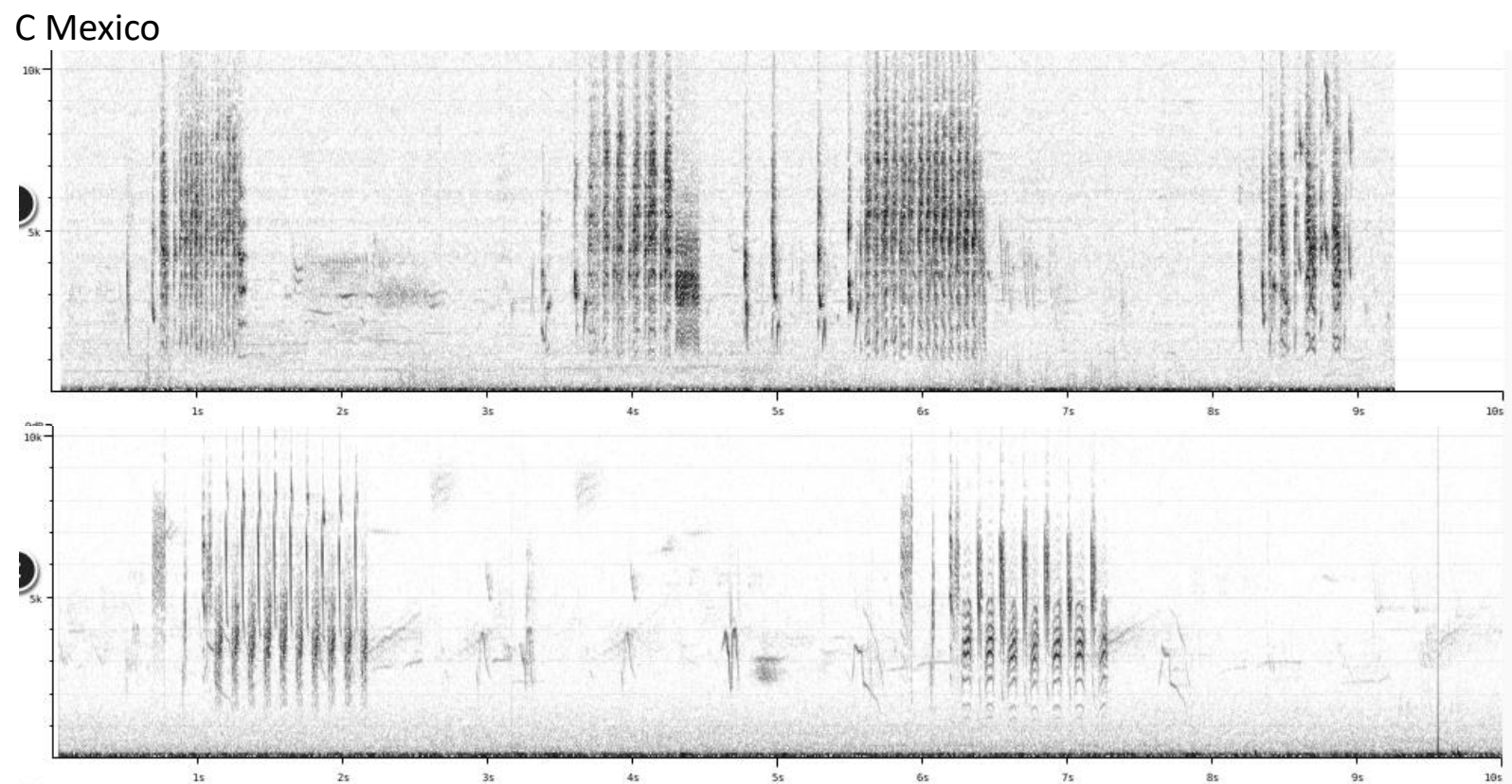

Guatemala

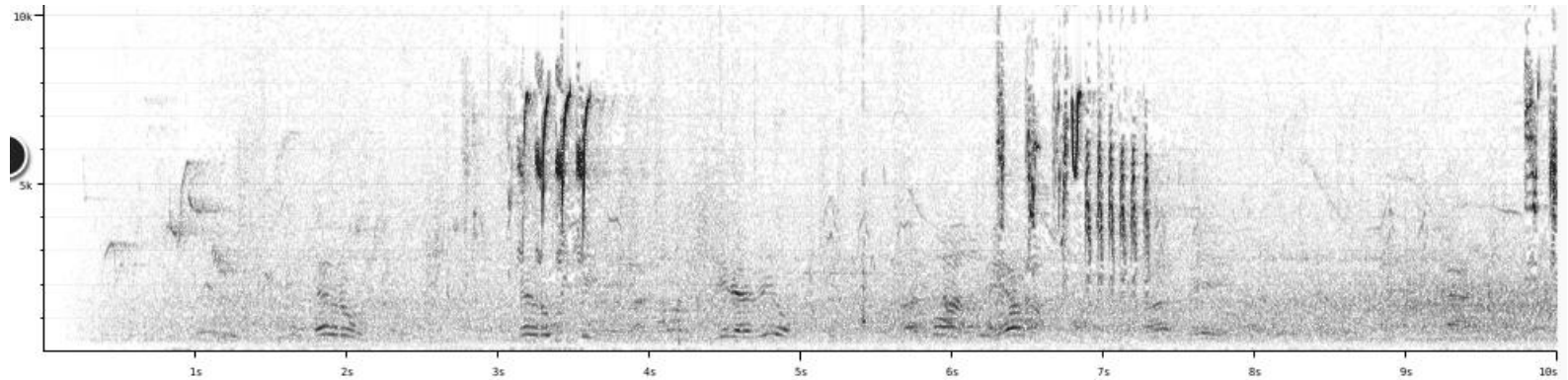

Honduras

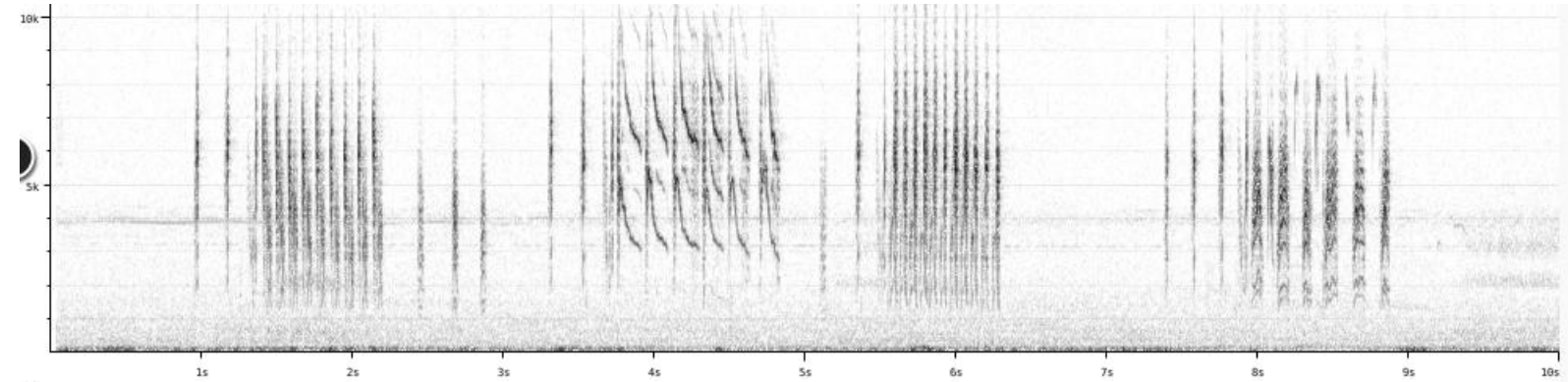

\section{Costa Rica}

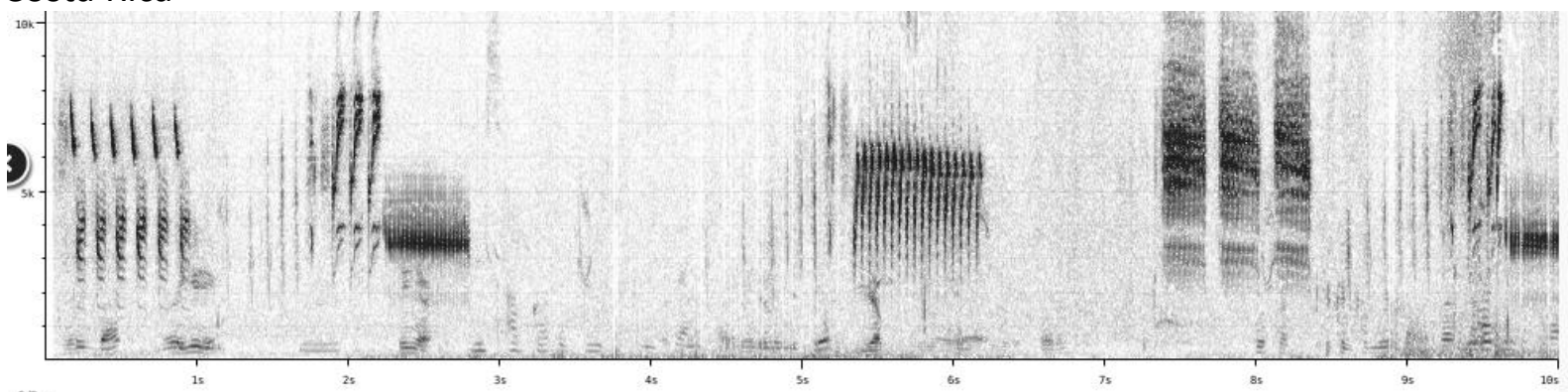




\section{HANDBOOK OF THE \\ BIRDSPF THE WORLD}

\section{ORNITHOLOGICAL NOTES}

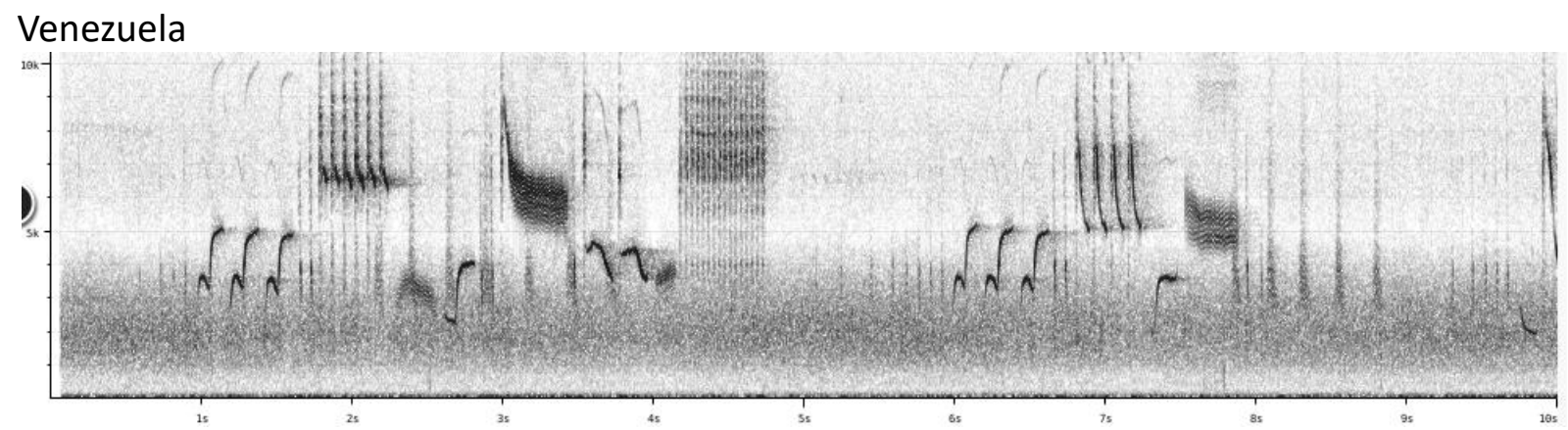

Colombia

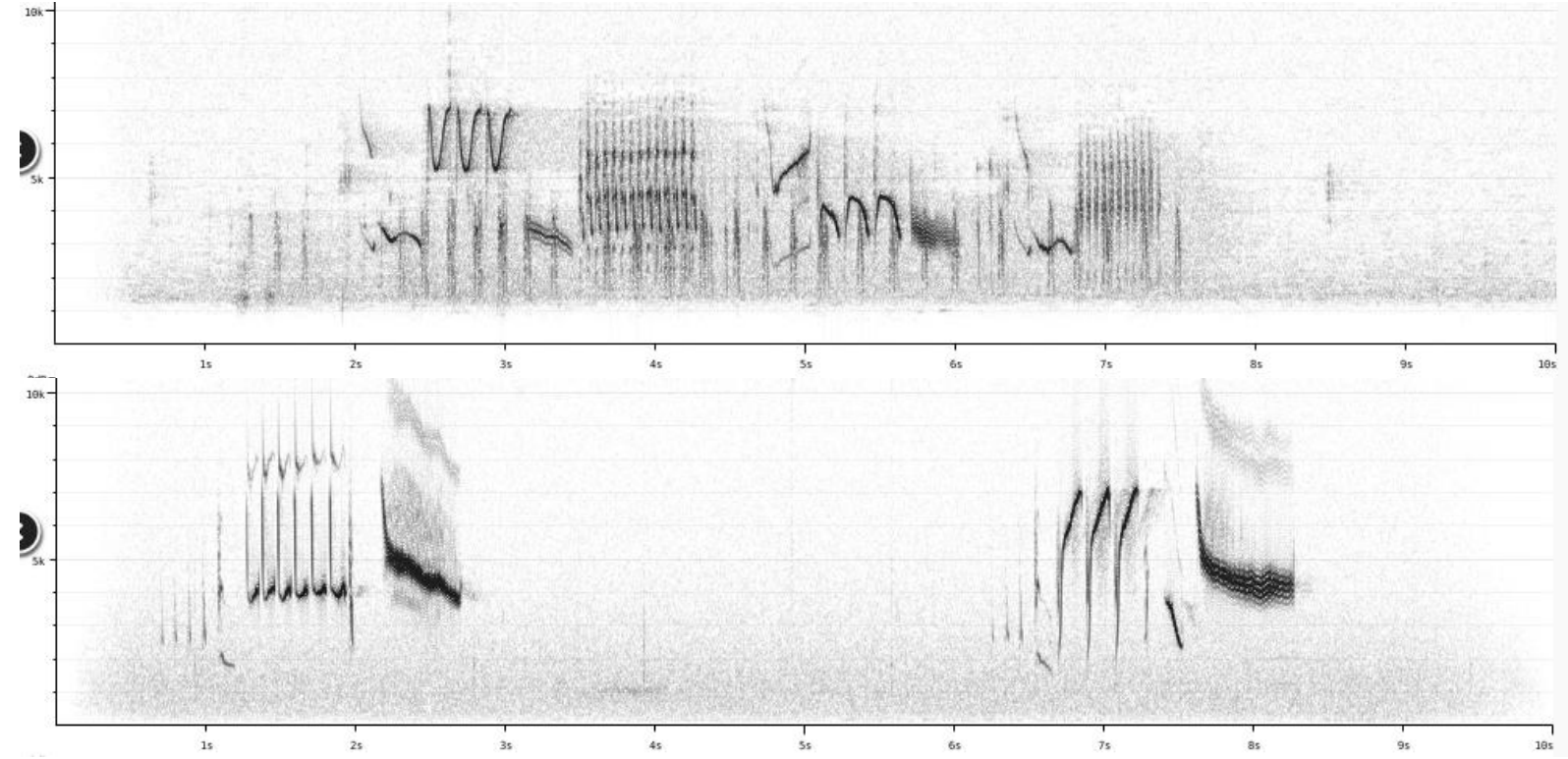

Peru

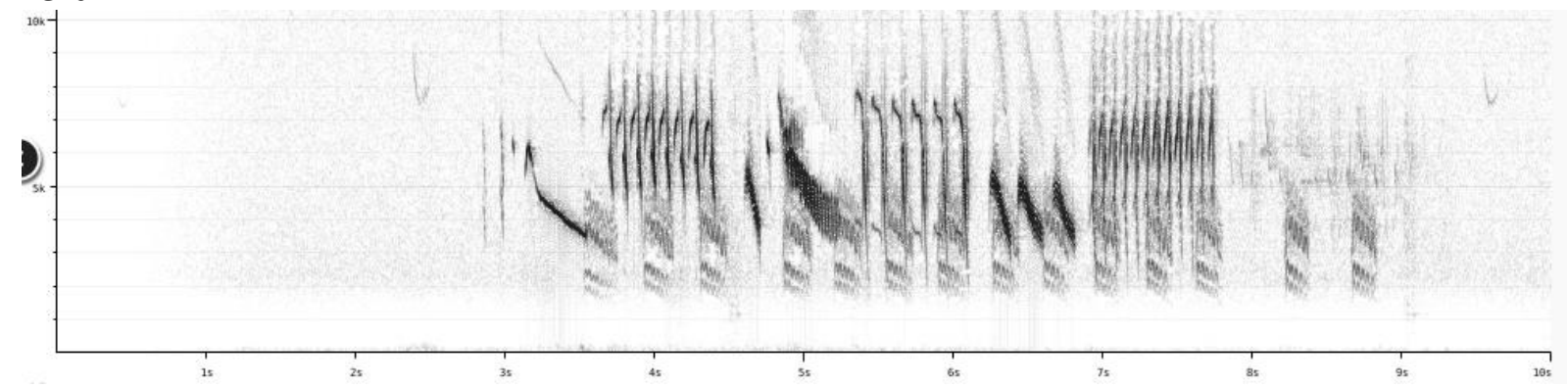

Argentina

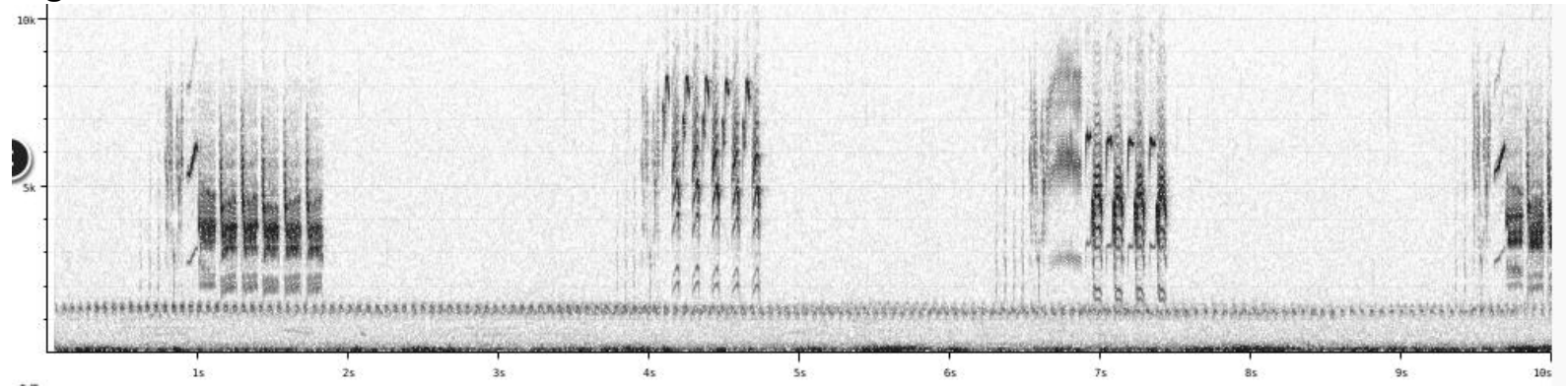



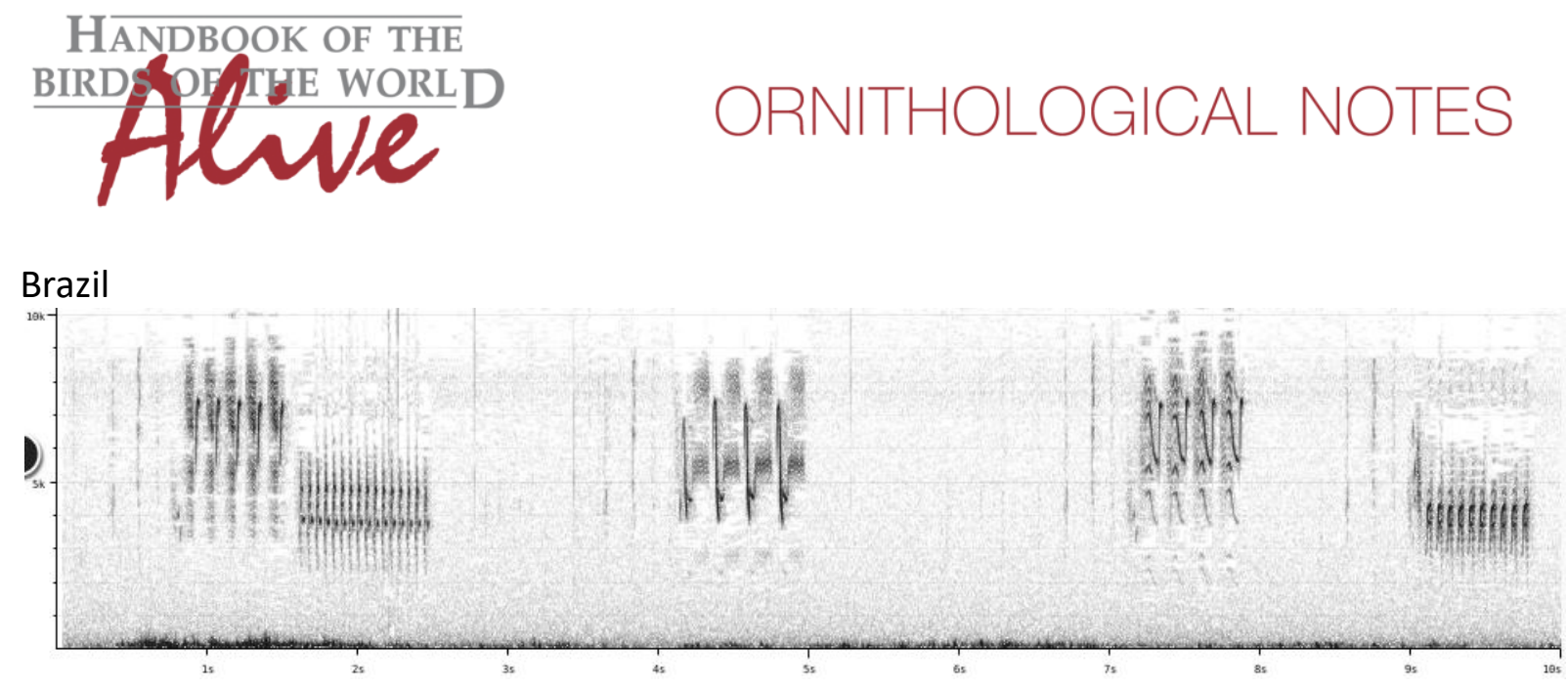

stellaris clearly differs from all other races by its simple, uniform song.

Differences could be expressed and quantified based on e.g. the lower number of (truly) different phrases (2-3) within a song series, the lower \# of different notes within a phrase (3) and the lack of notes with longer duration (1-2).

(Repeating the same phrase or not, and amount of different notes used within a phrase are two different things, for which the two first above listed parameters can be considered independent. E.g. you can have a phrase with many different notes which is repeated all the time, or you can have a different phrase all the time but with just one or two distinct notes being used, etc.).

When applying Tobias criteria, this would lead to a total vocal score of 5-6.

Among the neotropical taxa, it is clear that there is a huge amount of variation, with birds of the Andes from Venezuela to Peru having a much more complex song including whistles, compared to birds $\mathrm{N}$ and $\mathrm{S}$ of this region. A detailed analysis may reveal clear vocal groups here as well, and such study is thus highly recommended.

This note was finalized on 27th April 2016, using sound recordings available on-line at that moment. We would like to thank in particular the many sound recordists who placed their recordings for this species on XC.

\section{References}

Tobias, J.A., Seddon, N., Spottiswoode, C.N., Pilgrim, J.D., Fishpool, L.D.C. \& Collar, N.J. (2010). Quantitative criteria for species delimitation. Ibis 152(4): 724-746.

\section{Recommended citation}

Boesman, P. (2016). Notes on the vocalizations of Sedge Wren (Cistothorus platensis). HBW Alive Ornithological Note 285. In: Handbook of the Birds of the World Alive. Lynx Edicions, Barcelona. (retrieved from http://www.hbw.com/node/1251727 on 12 October 2016). 